\title{
Fishing for Drugs from Nature: Zebrafish as a Technology Platform for Natural Product Discovery
}

Author

Affiliation
Alexander D. Crawford ${ }^{1}$, Camila V. Esguerra ${ }^{2}$, Peter A. M. de Witte ${ }^{1}$

Department of Pharmaceutical Sciences, Katholieke Universiteit Leuven, Leuven, Belgium

Stem Cell Institute and Department of Musculoskeletal Sciences, Katholieke Universiteit Leuven, Leuven, Belgium

\author{
Key words \\ - zebrafish \\ - Danio rerio \\ - bioassay-guided fractiona- \\ tion \\ - chemical genetics \\ - in vivo drug discovery
}

received December 28, 2007 revised February 14, 2008 accepted February 18, 2008

\section{Bibliography}

DOI 10.1055/s-2008-1034374 Planta Med 2008; 74: 624-632 (c) Georg Thieme Verlag KG Stuttgart · New York

Published online April 7, 2008 ISSN 0032-0943

\section{Correspondence}

\section{Alexander D. Crawford}

Department of Pharmaceutical Sciences

Katholieke Universiteit Leuven Herestraat 49

3000 Leuven

Belgium

Tel.: +32-16-330-417

alexander.crawford@pharm.

kuleuven.be

\section{Peter A. M. de Witte}

Department of Pharmaceutical Sciences

Katholieke Universiteit Leuven

Herestraat 49

3000 Leuven

Belgium

Tel.: +32-16-323-432

peter.dewitte@pharm.

kuleuven.be

\section{Abstract \\ $\nabla$}

Emerging challenges within the current drug discovery paradigm are prompting renewed interest in natural products as a source of novel, bioactive small molecules. With the recent validation of zebrafish as a biomedically relevant model for functional genomics and in vivo drug discovery, the zebrafish bioassay-guided identification of natural products may be an attractive strategy to generate new lead compounds in a number of indication areas. Here, we review recent natural product research using zebrafish and evaluate the potential of this vertebrate model as a discovery platform for the systematic identification of bioactive natural products.

\section{Current Trends and Challenges in Natural Product Discovery \\ $\nabla$}

Natural products - referring here to small molecules produced by living organisms, particularly secondary metabolites - are an excellent yet currently underutilized source of chemical diversity for drug discovery. Bioactive compounds isolated from plants, fungi and bacteria have given rise to a wide range of human therapeutics, and numerous others are effective tools in cell biology, biochemistry and pharmacology. Despite this record of success, the field of natural product research has nonetheless witnessed a significant decline in the past two decades, due in large measure to the emergence of target validation, combinatorial chemistry and high-throughput screening as a new paradigm for drug discovery [1]. Several challenges unique to natural products have contributed to this trend as well, including the difficulties associated with isolating pure compounds from crude extracts, identifying their mechanism of action, and synthesizing these oftentimes highly complex structures [2], [3].

Conversely, the overall effectiveness of targetdriven drug discovery has recently been called into question [4], especially with respect to the limitations of combinatorial chemistry in terms of providing sufficient structural diversity for the identification of bioactive, drug-like compounds. Furthermore, there is a growing appreci- ation that natural products are privileged structures that have been evolutionarily selected on the basis of their ability to functionally interact with biological macromolecules [3]. Interest in natural products as a complementary, promising source of novel leads for drug discovery will therefore likely continue to expand.

Another drawback to target-driven drug discovery is the reduced complexity of screening assays - usually involving the ultra-high-throughput analysis of compound interactions with single targets, but too often giving rise to lead compounds that do not perform well in vivo [4]. The increasing awareness of this limitation is fueling interest in novel, high-content bioassays which enable target-independent screening and function-based identification of small molecules. Although cell-based screening assays using pathway-specific reporters are already a step in the right direction, bioassays based on intact, living organisms such as zebrafish provide an additional degree of physiological relevance that is difficult to match in vitro.

\section{Advantages of Zebrafish as a Model Organism}

Zebrafish have recently emerged as a powerful model for the rapid analysis of gene function and small-molecule bioactivity in a variety of in- 
dications [5]. Because of their high genetic, physiological and pharmacological similarity to humans, zebrafish are well-suited for the identification of bioactive natural products with therapeutic potential. The primary advantages of zebrafish as a model organism include the small size of embryos and larvae with which most tests can be performed $(1-5 \mathrm{~mm}$, depending on developmental stage), the high fecundity of adult zebrafish (hundreds of offspring per breeding pair per week), the optical transparency of embryos and larvae (allowing easy visualization of internal organs and tissues), and the speed at which these develop ex utero ( $\bullet$ Fig. 1 ). These features combine to create an ideal in vivo model suitable for medium-throughput phenotypic screening in microtiter plates. With regard to testing the bioactivity of small molecules, a key advantage of using zebrafish embryos and larvae is that compounds can simply be added to the (non-sterile) water surrounding them, further increasing screening throughput (for many phenotypic assays, hundreds of samples can be tested per day per investigator).

The zebrafish (Danio rerio) - a diploid minnow of the teleost family Cyprinidae, indigenous to the Ganges River Basin - was first established as a genetic model in the 1970s by Streisinger and colleagues [6]. This species was subsequently exploited for large-scale forward genetic screens by the laboratories of Nüsslein-Volhard and Driever using ENU mutagenesis [7], [8], and by Hopkins and colleagues using retroviral insertional mutagenesis [9]. While the primary purpose of these screens was to elucidate the genetic mechanisms of vertebrate development, several were designed to identify biomedically relevant genes, such as those regulating the growth, differentiation and function of tissues and organs. Examples include ENU mutagenesis screens for the isolation of zebrafish mutants with defects in cartilage development [10], hematopoiesis [11], and cardiovascular development [12]. More recent forward genetic screens include assays for gastrointestinal function [13], vascular development [14], and epilepsy [15].
Within the past decade, zebrafish have also become a versatile vertebrate model for reverse genetics. Antisense morpholino phosphorodiamidate oligonucleotides [16] - commonly referred to as "morpholinos" - are effective tools in zebrafish for the specific inhibition of gene expression [17]. Dose-dependent "knockdowns" of gene expression can be achieved by the microinjection of morpholinos into single-cell-stage embryos ( $\bullet$ Fig. 1b), wherein the antisense oligonucleotides can be designed to inhibit either the translational initiation of mRNAs or the splicing of hnRNAs. Numerous genes have been functionally analyzed in zebrafish in this manner [18], including several identified within the context of large-scale reverse genetic screens [19], [20], [21]. In addition, it is now possible to use morpholinos for inducible gene knockdowns, via the light-activated cleavage of photolabile complementary oligonucleotides that block their ability to bind their target RNA [22]. Conversely, the efficacy of siRNA in zebrafish embryos remains a topic of debate [23], [24], although it was recently shown that shRNA expressed from an integrated transgene effectively inhibits gene expression in developing embryos [25].

Transgenesis methods in zebrafish are well-established, allowing the straightforward generation of transgenic lines expressing fluorescent reporter proteins under the control of tissue-specific promoters. Insertional mutagenesis screens using enhancer-trap and gene-trap transposons and retroviral vectors are also providing many novel reporter lines [26]. Collectively, this growing collection of transgenic zebrafish lines represents a powerful resource for the systematic elucidation of organogenesis, and for many aspects of cell biology to be performed in vivo [27]. In the area of angiogenesis, for example, transgenic lines have been used for the detailed anatomic analysis of embryonic blood vessel formation [28], as well as to carry out both genetic [14] and compound screens [29] for the identification of novel genes and small molecules modulating these processes.

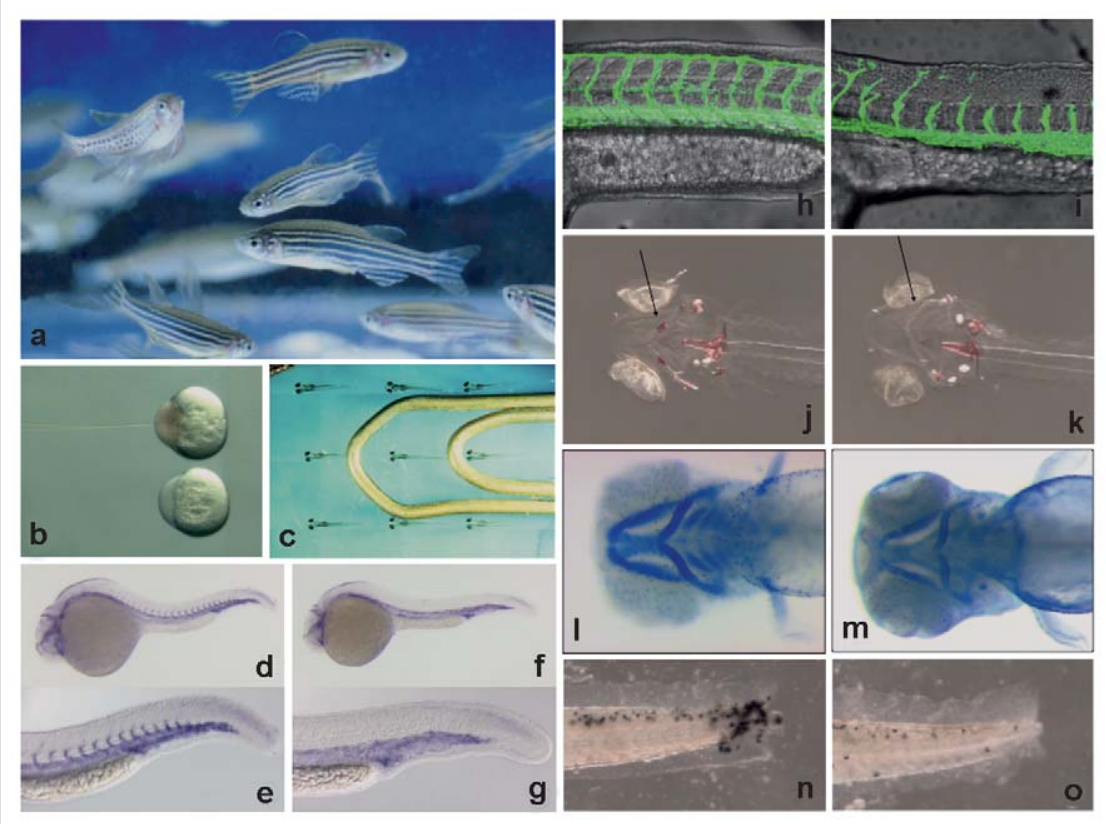

Fig. 1 Zebrafish as a model organism for drug discovery. a Adult zebrafish; b microinjection of one-cell stage embryos; c agarose-embedded larvae at 5 days post-fertilization (dpf), revealing size in relation to paperclip; $\mathrm{d}$, e visualization of developing vasculature in embryo at 30 hours post-fertilization (hpf) by whole-mount in situ hybridization with flk-1 RNA probe, revealing outgrowing intersegmental vessels (ISVs); f, g embryo microinjected with antisense morpholino oligomer (MO) targeting vascular endothelial growth factor (VEGF), exhibiting lack of ISV outgrowth; $h$ visualization of developing vasculature in transgenic fli-1:eGFP embryo at $40 \mathrm{hpf}$ by laser multiphoton confocal microscopy; i embryo treated with PI3K inhibitor wortmannin, exhibiting reduced ISV outgrowth; j visualization of bone formation in larva at $10 \mathrm{dpf}$ by whole-mount Alizarin red staining; $k$ larva treated with glucocorticoid prednisolone, exhibiting reduced bone formation; I visualization of cartilage formation in untreated embryo at $3 \mathrm{dpf}$ by wholemount Alcian blue staining; $m$ embryo microinjected with antisense $\mathrm{MO}$ targeting gene involved in craniofacial development, exhibiting reduced staining of, and/or missing, cartilage elements $\mathrm{n}$ visualization of leukocyte migration by whole-mount myeloperoxidase staining in larva at $4 \mathrm{dpf}$ with tail fin injury; o larva with tail fin injury treated with the crude methanolic extract of an anti-inflammatory East African medicinal plant (Fabaceae family), exhibiting reduced leukocyte migration to site of injury. 
Recent innovations in zebrafish transgenesis include an elegant approach for targeted ablations - e.g., for the generation of zebrafish larvae lacking pancreatic beta cells, which can then be observed to regenerate - through the tissue-specific expression of bacterial nitroreductase followed by incubation of the transgenic zebrafish embryos in metronidazole [30]. In addition, a novel technique has been reported for the induction of transgene expression in zebrafish using small-molecule agonists of the insect-specific ecdysone receptor (EcR) [31], [32]. This approach allows for the dose-dependent regulation of transgene activity simply through the addition of EcR agonists to the embryo medium - an elegant tool which enables the precise temporal control of gene expression and which will therefore facilitate the molecular dissection of signaling pathways during embryonic development.

As with any experimental system, there are clearly also limitations in working with zebrafish as a model organism. First, given that most screens are carried out at early life stages, it is important to consider the physiological differences between embryonic or larval fish and adult mammals. In any case, bioactive small molecules identified in zebrafish should ideally be validated in an appropriate rodent assay before being prioritized as lead compounds. Second, depending on their molecular weight and hydrophobicity, not all small molecules are readily absorbed by embryos and larvae, possibly leading to false negatives during screening. Finally, given that zebrafish are vertebrates, countryspecific animal rights legislation and institutional bioethics regulations need to be taken into account when planning experiments. It is worth noting that there are several jurisdictions which do not consider unhatched fish embryos to be vertebrates in the full legal sense, enabling certain large-scale screens to be carried out with minimal administrative requirements.

\section{Zebrafish-Based Analysis of Natural Products and other Small Molecules \\ $\nabla$}

Zebrafish were first proposed as an in vivo model for small-molecule drug discovery over fifty years ago [33]. This initial study investigated the utility of zebrafish embryos and larvae for screening both natural products and synthetic compounds, especially with respect to their effects on cell division and differentiation. In addition to numerous studies over the following decades focusing on the detection or characterization of environmental contaminants [34], [35], developing zebrafish embryos have been used to determine the embryotoxicity or teratogenicity of several natural products consumed by humans, including various flavonoids [36]; delta-9-tetrahydrocannabinol, the major psychoactive constituent of marijuana [37]; and arecoline, the major alkaloid in betel nuts [38]. In a related approach, adult zebrafish were recently utilized to confirm the piscicidal properties of arylnaphthalide lignans isolated from Phyllanthus piscatorum, an ethnomedicinal plant used by the Amazonian Yanomami as a fish poison and antifungal remedy [39], [40].

Despite an appreciable history of pharmacological investigation dating back over half a century, it is only within the past decade that large-scale screens of small molecules have been performed using zebrafish-based assays. Initial compound screens have focused on the analysis of combinatorial chemistry libraries - encompassing up to 20,000 molecules - for their ability to induce a variety of developmental phenotypes [41], [42], [43]. More recently, small-molecule screening in zebrafish has been em- ployed to identify synthetic compounds acting as suppressors of aortic coarctation, a congenital heart defect [44], as modulators of pigmentation [45], [46], [47], as cell cycle inhibitors [48], as regulators of heart rate [49], and as modulators of tissue regeneration [50].

Not all large-scale screens performed in zebrafish have been designed to find potential therapeutics, however. For example, bioactive small molecules can also be used to induce index phenotypes - i. e., disease-like states - which can subsequently be exploited in modifier screens to look for genetic or chemical suppressors of this phenotype. Using this approach, compounds have been identified that induce reversible hemolytic anemia [51]. In a related approach, compounds were screened for their ability to act as radiation sensitizers [52]. Taken together, these studies have clearly established zebrafish as a facile model for in vivo drug discovery [5], [53].

\section{Zebrafish-Based Analysis of Plant Extracts}

$\nabla$

With respect to natural product discovery, no large-scale screens of compounds of natural origin have yet been reported in zebrafish. In addition, beyond the natural products mentioned above as having been analyzed in zebrafish, very few zebrafish-based studies of plant extracts have been reported to date. Furthermore, the potential of in vivo zebrafish assays for the bioactivity-guided fractionation of complex natural extracts is only beginning to be explored.

One of first reports in this direction describes the use of transgenic zebrafish to characterize the pro-angiogenic properties of the East Asian medicinal plant Angelica sinensis (dong quai), but does not mention the isolation of any bioactive constituents. In this study, Lee and colleagues first demonstrate that an Angelica sinensis extract stimulates proliferation, migration, and tube formation in human umbilical vein endothelial cells (HUVECs). They then substantiate these findings through the observation of increased subintestinal vessel (SIV) growth in extract-treated fli-1:EGFP transgenic zebrafish, which have endothelial cell-specific expression of green fluorescent protein [54].

Another report, presented at the 2006 American Society of Pharmacognosy Meeting, goes one step further with respect to isolating bioactive constituents. Here, $\mathrm{Xu}$ and colleagues report the bioactivity-guided purification of three anti-angiogenic compounds from the anti-inflammatory Chinese medicinal plant Tripterygium wilfordii (lei gong teng), in this case using wholemount histochemistry (alkaline phosphatase staining) to visualize blood vessel development in zebrafish embryos [55]. These three molecules include the known angiogenesis inhibitors triptolide (a diterpene triepoxide with immunosuppressive properties and inhibitory activity on $\mathrm{NF}-\kappa \mathrm{B}$ ) and celastrol (a triterpenoid with anti-inflammatory and antioxidant activity), as well as cangoronine (a triterpenoid with no previously reported bioactivity, but with only marginal anti-angiogenesis activity in this zebrafish assay).

At the 2007 European Zebrafish Genetics and Development Meeting, Patton and colleagues describe the zebrafish bioassayguided fractionation, using the induction of an early embryonic phenotype as an assay, to partially isolate a cyclopamine-like activity from a crude plant extract [56]. It is worth noting that cyclopamine, a steroidal jerveratrum alkaloid, was originally isolated from Veratrum californicum (corn lilly) by virtue of its ability to induce cyclopia in newborn sheep, and that more recently the 
mechanism of action of this teratogen was found to be the potent inhibition of hedgehog signaling [57]. Because of this specific activity, cyclopamine is now an important reagent for the control of embryonic stem cell differentation in vitro [58]. Given the important role of aberrant hedgehog signaling in several human cancers (including basal cell carcinoma, medulloblastoma and rhabdomyosarcoma), these findings qualify cyclopamine and similarly acting natural products as attractive lead compounds for the development of novel anti-cancer therapeutics [59]. Indeed, the zebrafish-based screening of dietary alkaloids recently revealed several of these - most of them similar in structure to cyclopamine - to have similar activities as inhibitors of hedgehog signaling [60]. As such, using zebrafish embryos as an in vivo bioassay may be a promising strategy for the identification of novel natural products that inhibit hedgehog signaling or other developmental pathways relevant for human disease.

In order to further examine the potential of zebrafish as a platform for natural product discovery, our laboratory recently initated an effort based on the zebrafish-mediated screening and bioactivity-guided fractionation of crude plant extracts [61]. Using high-performance thin-layer chromatography (HP-TLC) in combination with high-resolution electrospray ionization mass spectrometry (HR-ESI-MS) and chemical database analysis, we were able to rapidly isolate emodin and an abietane diterpenoid, coleon A lactone, from the crude methanolic extracts of two East African medicinal plants (Oxygonum sinuatum and Plectranthus barbatus, respectively). The zebrafish assay used for the activity-guided isolation of these two compounds examined their ability to potentiate a sub-effective dose of the anti-angiogenic compound SU5416, an indoline inhibitor of the vascular endothelial growth factor (VEGF) receptor [62], in fli-1:EGFP transgenic embryos. In this context it is worth noting that emodin, an inhibitor of the protein kinase CK2 [63], is known to restrict angiogenesis both in vitro [64] and in vivo [65], and that coleon A lactone was subsequently also found by our investigation to inhibit endothelial cell proliferation and tube formation in vitro. This study illustrates the utility of zebrafish, in combination with HP-TLC and HR-ESI-MS, for the rapid and cost-effective bioactivity-guided isolation of natural products from crude plant extracts. The primary advantages of this approach are (1) the requirement for only sub-milligram quantities of crude extracts, fractions, and pure compounds for an in vivo analysis of bioactivity, thereby avoiding the use of preparative column chromatography during initial screening stages; and (2) the rapid identification of known compounds, thereby achieving cost-effective dereplication early in the discovery process and facilitating the prioritization of laboratory resources for the pursuit of novel molecules. Furthermore, it highlights the potential of performing natural product discovery in zebrafish using screening assays designed to identify novel modulators of specific signaling pathways and/or novel potentiators of existing drugs.

\section{Chemical Genetics in Zebrafish}

\section{$\nabla$}

A key challenge in natural product discovery is the identification of the mechanism of action, and ultimately the biological target, of bioactive compounds. Chemical genetics - the elucidation of biological function through the use of small molecules - is a particularly powerful strategy in this regard, and is finding increasing application in a number of model systems. Zebrafish represent a powerful system with which to explore the mechanism of action of natural products and other small molecules, as demonstrated in several recent reports described below. It is worth noting that such studies usually rely on a combination of experiments in zebrafish (for phenotypic data to ascertain pathway specificity) and mammalian cells (for molecular and biochemical data to confirm these findings).

One of these studies identified the biological target of apratoxin A, a cyclodepsipeptide cytotoxin isolated from the marine cyanobacterium Lyngbya majuscula [66]. Apratoxin A is one of several cyanobacterial metabolites with potent anti-tumor activity, and although two of these (cryptophycin and dolastatin 10) have been shown to bind microtubules, the other cyanobacterial cytotoxins remain elusive in terms of their mode of action. In an elegant approach, Luesch and colleagues first combined gene expression profiling and genome-wide, arrayed cDNA overexpression to reveal that apratoxin A induces apoptosis in mammalian cells via the modulation of fibroblast growth factor (FGF) signaling. After being shown to inhibit the phosphorylation-dependent activation of STAT3, a downstream effector of FGF signaling, apratoxin A was then found to affect FGF-dependent developmental processes in zebrafish embryos. These phenotypic defects were similar to those induced by the FGF receptor inhibitor SU5402, and included the downregulation of the FGF target gene mkp3 [67].

Another recent study using zebrafish focused on the mechanism of action of fumagillin, a sesquiterpene antibiotic isolated from the airborne saprophytic fungus Aspergillus fumigatus [68] and currently used to treat microsporidiosis in humans and honeybees. Fumagillin and its analogue $\mathrm{O}$-(chloracetyl-carbamoyl)fumagillol (TNP-470) have been characterized as potent angiogenesis inhibitors [69], and an $\mathrm{N}$-(2-hydroxypropyl)methacrylamide (HPMA) copolymer conjugate of TNP-470 is currently in latestage preclinical development as an anti-angiogenesis drug for the treatment of solid tumors [70]. Despite its known inhibition of the methionine aminopeptidase MetAP-2 [71], this interaction alone did not fully explain fumagillin's biological properties. To further explore how the restriction of MetAP-2 activity modulates angiogenesis, Crews and colleagues treated developing zebrafish embryos with TNP-470, inducing a truncated tail dysmorphology that through phenotype database analysis was found to be highly reminiscent of the Wnt5a mutant pipetail. A similar phenotype was induced through antisense morpholino oligonucleotides directed against MetAP-2, suggesting a functional link between MetAP-2 and Wnt5a signaling. Further experiments in mammalian cells indicated that this interaction occurs in the context of non-canonical Wnt signaling (i.e., via the receptor Frizzled2), and that the point of action of TNP-470 is downstream of Frizzled 2 and upstream of the non-canonical Wnt effectors CamKII, c-Jun, and RhoA [72], [73].

Behavioral assays in zebrafish have also recently been used to examine the mechanism of action of salvinorin A, a physchoactive trans-neoclerodane diterpenoid isolated from Salvia divinorum [74]. This Lamiaceae species has a long history of traditional use as an entheogen by Mazatec shamans in Central America - an ethnomedicinal application supported by the fact that salvinorin A is a potent kappa-opioid receptor agonist and currently the most powerful known hallucinogen of natural origin. By examining the swimming behavior and conditioned place preference of salvinorin A-treated adult zebrafish, it was possible to ascertain reinforcing properties that were fully reversible by both nor-binaltorphimine (a kappa-opioid receptor antagonist) and rimonabant (a CB1 cannabinoid receptor antago- 
nist), implicating both pathways in mediating the rewarding effects of salvinorin A and further establishing zebrafish as a useful model for addiction research (see also [75]).

A further example of the power of chemical genetics in zebrafish is the recent description of dorsomorphin, a novel small-molecule inhibitor of bone morphogenic protein (BMP) signaling [76]. In this study, Peterson and colleagues screened 7,500 synthetic compounds, identifying one that perturbed dorsoventral axis formation in early embryos - a phenotype highly reminiscent of transgenic zebrafish overexpressing noggin (an extracellullar inhibitor of BMP) and lost-a-fin mutants (with a loss-offunction allele of the BMP receptor ALK8). Rescue experiments in zebrafish embryos showed that dorsomorphin suppressed the ventralized phenotype induced by antisense-mediated inhibition of chordin (another BMP inhibitor) - an elegant confirmation of dorsomorphin's own ability to block BMP signaling. Subsequent biochemical analysis of BMP pathway components in dorsomorphin-treated mammalian cells confirmed that this compound specifically affects SMAD 1/5/8-dependent signaling and not MAPK activity, both of which are stimulated by BMP type I receptor activation. As expected from an inhibitor of BMP signaling, dorsomorphin-treated zebrafish larvae exhibited reduced bone mineralization. Finally, dorsomorphin proved its utility as a new pharmacological tool in mice, helping to elucidate the role of BMP signaling in iron homeostasis.

\section{Zebrafish Assays Useful for Natural Product Discovery \\ $\nabla$}

Beyond the plethora of bioassays mentioned above and in - Table 1, we would like to highlight three areas of particular applicability for zebrafish-mediated natural product discovery: immunity and inflammation, epilepsy, and cardiotoxicity. Despite their clear in vivo relevance, rodent-based assays in these areas have inherent disadvantages in terms of cost and throughput that render them less suitable as a primary screening platform for the discovery of novel, bioactive small molecules. Zebrafish larvae, on the other hand, are an ideal in vivo system for such applications, and are clearly appropriate for mediumthroughput screening of plant extracts and natural products.

\section{Immunity and inflammation}

With potential utility for the discovery of novel antimicrobial agents, several zebrafish models for bacterial pathogenesis have been reported, most of which rely on the use of Mycobacterium marinum [77], [78]. Other studies have examined the pathogenesis and inflammatory response of zebrafish embryos to bacterial infection, for example, by Edwardsiella tarda, which results in the significant upregulation of interleukin- $1 \beta$ and TNF $\alpha$ as determined by qRT-PCR [79]. Moving towards an easier and lowerrisk model for the innate immune reponse to bacterial infection in vivo, Watzke and colleagues have recently shown that bacterial lipopolysaccharides (LPS) are able to induce a very similar upregulation of these two pro-inflammatory cytokines in zebrafish embryos [80].

Zebrafish larvae are now also well-established as an in vivo model for inflammation. In 2001, Lieschke and colleagues first showed that leukocytes, including both circulating granulocytes and macrophages, could be readily visualized in zebrafish larvae though whole-mount histochemical staining for myeloperoxidase activity within the first 48 hours after fertilization, and that transection of part of the larval tail stimulated the migration and accumulation of leukocytes within hours after injury [81]. More recently, two other groups have generated transgenic lines expressing EGFP under the control of the myeloperoxidase promoter, enabling the direct visualization of live leukocytes and therefore the observation of the inflammatory response in real time [82], [83]. In combination with other possibilities to analyze the inflammatory response, for example, using transgenic embryos with EGFP-expressing early macrophages [84], the zebrafish clearly has the potential to be an effective system for the identification of anti-inflammatory natural products and other small molecules.

\section{Epilepsy}

Zebrafish have recently also emerged as a novel experimental model of epilepsy [85]. Baraban and colleagues first described the response of zebrafish larvae to pentylenetetrazol (PTZ), a convulsant widely used to induce seizures in rodents [86]. This investigation confirmed the ability of PTZ to induce a dose-dependent series of stereotypical behaviors, including clonus-type convulsions characteristic of epilepsy in mammals. Electrophysiological recordings from the brains of PTZ-treated zebrafish larvae indicated epileptiform discharges that were reduced through the application of anti-epileptic drugs such as valproate and diazepam. Baraban and colleagues next performed a forward genetic screen to identify zebrafish mutants insensitive to the effects of PTZ, with the goal of elucidating the genetic basis of seizure resistance [15].

In order to facilitate the discovery of novel anti-epileptic drugs, Goldsmith and colleagues have recently developed an automated tracking system to monitor the movement of zebrafish larvae in microtiter plates [87]. Using this methodology, 13 of 14 known anti-epileptic drugs were found to suppress PTZ-induced behavioral abnormalities, thereby validating the suitability of zebrafish for the high-throughput screening of potential anti-epileptic compounds. Intruigingly, domoic acid (DA, a phycotoxin produced by Pseudo-nitzschia diatoms) was recently found to increase the susceptibility of zebrafish larvae to PTZ, further confirming the role of DA in seizure induction in marine mammals exposed to algal blooms [88]. Taken together, the progress in this area underscores the potential of zebrafish as a promising in vivo bioassay for the discovery of anti-epileptic natural products.

\section{Cardiotoxicity}

Another noteworthy advantage of using zebrafish larvae for compound screening is that various aspects of cardiotoxicity can be investigated at a very early stage in the drug discovery process. Cardiotoxicity is one of the more common adverse effects seen for many new chemical entities, and the clinical development of numerous drug candidates has been discontinued because of their tendency to induce cardiac arrhythmias such QT prolongation and torsades de pointes. One of the primary causes of cardiotoxicity are unforeseen interactions of compounds with the HERG potassium channel (the protein product of the $\mathrm{KCNH} 2$ gene, and also referred as the $\mathrm{K}_{\mathrm{v}} 11.1$ potassium channel), responsible for the repolarizing $\mathrm{I}_{\mathrm{Kr}}$ current in the cardiac action potential. Despite this appreciable risk, drugs are normally only examined relatively late in pre-clinical testing using, for example, isolated guinea pig hearts, which requires multi-milligram amounts of each compound to be tested.

With their requirement for only microgram quantities of any given compound to be analyzed, combined with the ability to 
Table 1 Overview of selected zebrafish assays with potential relevance for natural product discovery

\begin{tabular}{|c|c|c|c|}
\hline Indication & Zebrafish Assay & Description & Reference \\
\hline \multirow[t]{13}{*}{ Cancer } & $\begin{array}{l}\text { Oncogene-induced } \\
\text { tumors }\end{array}$ & Heat-shock induction of Ras-dependent tumors in Cre/loxP transgenics & [93], [94] \\
\hline & & Cre RNA induction of Myc-dependent tumors in loxP transgenics & [95] \\
\hline & & T-cell leukemia induced by Myc overexpression & {$[108]$} \\
\hline & $\begin{array}{l}\text { Tumor suppressor- } \\
\text { induced tumors }\end{array}$ & Target-selected ENU mutagenesis screen for $\mathrm{p} 53$ mutations & [96] \\
\hline & $\begin{array}{l}\text { Mutagen-induced } \\
\text { tumors }\end{array}$ & Transplantation of isogeneic tumor cells between clonal zebrafish lines & [97] \\
\hline & Tumor imaging & Ultrasound imaging of liver tumors in adult zebrafish & [98] \\
\hline & Tumor metastasis & Transplantation of human tumor cells into zebrafish embryos & $\begin{array}{l}{[99],[100]} \\
{[101],[102]}\end{array}$ \\
\hline & Radiation sensitivity & Small-molecule screens for radiation sensitizers and protectants & $\begin{array}{l}{[52],[103]} \\
{[109]}\end{array}$ \\
\hline & Genomic instability & ENU mutagenesis screen for genomic instability mutants & [104], [105] \\
\hline & Cell migration & Antisense screen for genes affecting primordial germ cell migration & [19] \\
\hline & Cell cycle & Small-molecule screen for cell cycle inhibitors & [48] \\
\hline & & ENU mutagenesis screen for mitosis mutants & [105] \\
\hline & & Small-molecule screen for suppressors of mitosis mutant (crash and burn) & {$[106]$} \\
\hline \multirow[t]{2}{*}{ Skeletal disorders } & Cartilage formation & ENU mutagenesis screen for cartilage mutants & {$[10]$} \\
\hline & Osteoporosis & $\begin{array}{l}\text { Glucocorticoid-induced reduction of bone formation; characterization of bone } \\
\text { anabolic compounds }\end{array}$ & [110], [111] \\
\hline \multirow[t]{3}{*}{ Blood disorders } & Hematopoiesis & ENU mutagenesis screen for hematopoiesis mutants & {$[11]$} \\
\hline & & Small-molecule screen for inducers of reversible hemolytic anemia & [51] \\
\hline & Thrombosis & Laser-induced thrombosis in larvae & [112] \\
\hline \multirow[t]{8}{*}{$\begin{array}{l}\text { Cardiovascular } \\
\text { disorders }\end{array}$} & $\begin{array}{l}\text { Heart formation and } \\
\text { function }\end{array}$ & ENU mutagenesis screen for heart and cardiovascular mutants & {$[12]$} \\
\hline & & Small-molecule screen for suppressors of aortic coarctation mutant (gridlock) & [44] \\
\hline & Angiogenesis & $\begin{array}{l}\text { ENU mutagenesis screen for angiogenesis mutants using transgenic } \\
\text { reporter line }\end{array}$ & [14] \\
\hline & & $\begin{array}{l}\text { Small-molecule screen for anti-angiogenic compounds using transgenic } \\
\text { reporter line }\end{array}$ & [28], [29] \\
\hline & & Characterization of anti-angiogenic natural products in transgenic larvae & [107] \\
\hline & Cardiotoxicity & ENU mutagenesis screen for QT prolongation mutants & {$[92]$} \\
\hline & & Characterization of QT-prolonging drugs in zebrafish larvae & [89], [90], [91] \\
\hline & Heart rate & Small-molecule screen for modulators of heart rate & [49] \\
\hline \multirow{11}{*}{$\begin{array}{l}\text { Neurological } \\
\text { disorders }\end{array}$} & Epilepsy & Validation of anti-epileptic drugs in larvae with PTZ-induced seizures & [86], [87] \\
\hline & & ENU mutagenesis screen for seizure-resistant mutants & [15] \\
\hline & Addiction & Characterization of psychoactive drugs and drugs of abuse & $\begin{array}{l}{[74],[75],} \\
{[113]}\end{array}$ \\
\hline & & ENU mutagenesis screen for differences in cocaine sensitivity & [114] \\
\hline & Behavior and learning & ENU mutagenesis screen for embryos/larvae with behavioral defects & [115] \\
\hline & & Characterization of drug effects on non-associative learning in larvae & {$[116]$} \\
\hline & & Automated detection of behavioral defects & {$[117]$} \\
\hline & Neurodevelopment & ENU mutagenesis screen for enteric nervous system defects & [118] \\
\hline & Axon myelination & ENU mutagenesis screen for axon myelination defects & [119], [120] \\
\hline & Neurodegeneration & Transgenic line with overexpression of mutant human Tau protein & {$[121]$} \\
\hline & ALS & Transient transgenic model with overexpression of mutant human SOD protein & [122] \\
\hline \multirow{4}{*}{$\begin{array}{l}\text { Immunity and } \\
\text { inflammation }\end{array}$} & Bacterial infection & Characterization of immune response to bacterially infected larvae & [77], [79], [80] \\
\hline & & Small-molecule screening for antimicrobials in bacterially infected larvae & [78] \\
\hline & Inflammation & Histochemical visualization of leukocyte migration after injury & [81] \\
\hline & & Transgenic zebrafish lines for visualization of leukocyte migration & [82], [83], [84] \\
\hline \multirow[t]{3}{*}{ Metabolic disorders } & Lipid metabolism & ENU mutagenesis screen for defects in digestive physiology & {$[13]$} \\
\hline & Diabetes & $\begin{array}{l}\text { ENU mutagenesis screen for defects in pancreas formation using } \\
\text { transgenic reporter lines }\end{array}$ & [123] \\
\hline & Liver disease & ENU mutagenesis screens for liver formation and hepatomegaly & [124], [125] \\
\hline \multirow[t]{4}{*}{ Other } & Pigmentation & $\begin{array}{l}\text { Small-molecule screens for modulators of pigmentation and } \\
\text { melanocyte differentatiation }\end{array}$ & $\begin{array}{l}{[45],[46]} \\
{[47],[129]}\end{array}$ \\
\hline & Tissue regeneration & Small-molecule screen for modulators of tissue regeneration & [50] \\
\hline & Hearing loss & Characterization of ototoxic and otoprotective agents on larval hair cells & {$[126],[127]$} \\
\hline & Circadian rhythms & ENU mutagenesis screen for circadian rhythm mutants & [128] \\
\hline
\end{tabular}

Note that several mutant/transgenic lines are described above in terms of how they were generated (e. g., via ENU mutagenesis screens); the assays used for these screens and/or the mutant/transgenic lines themselves may be useful for characterizing screening natural products or other small molecules. 
readily observe heart function in transparent larvae, zebrafish are well-suited as a front-line assay for cardiotoxicity. In 2003, two laboratories validated zebrafish larvae as a reliable model to test compounds for their ability to induce QT prolongation [89], [90], [91]. These studies showed that 22 out of 23 compounds known to cause QT prolongation in humans induced bradycardia or atrioventricular block in zebrafish, and that similar effects were observed by the antisense-mediated knockdown of Zerg (encoded by $k c n h 2$, the zebrafish ortholog of human $\mathrm{KCNH} 2$, both of which share $99 \%$ amino acid identity in the pore domain of their protein products). In a related effort, one of the groups went on to establish a transgenic line with myocardium-specific expression of EGFP, and used this model together with automated fluorescence microscopy for the high-throughput screening of small molecules that modulate heart rate in zebrafish embryos [49]. More recently, another group isolated the mutation responsible for an inherited arrhythmia in zebrafish, determining the affected gene to be kcnh2 by genetic mapping and direct sequencing [92]. Together, these findings underscore the suitability of zebrafish to serve as a useful model for prescreening natural products and other small molecules for their potential risk to cause QT prolongation and other arrhythmias.

\section{Outlook}

$\nabla$

Zebrafish are now firmly established as a powerful research platform for many areas of biology and drug discovery. Given the relative ease with which natural products and other small molecules can be analyzed in zebrafish, it is conceivable that within the next decade the large majority of currently available plant and fungal extracts (and increasing numbers of microbial extracts) can be screened in a plethora of biomedically relevant assays - an undertaking not currently feasible using other in vivo models. Zebrafish-based assays have the capacity to facilitate the bioassay-guided fractionation of large numbers of bioactive extracts identified in such in vivo screens, and thereby to enable the isolation of numerous novel, bioactive natural products several of which are likely to be attractive lead compounds for the development of new, effective drugs.

\section{References}

1 Drews J. Die verspielte Zukunft: Wohin geht die Arzneimittelforschung? Basel: Birkhäuser Verlag; 1998

2 Clardy J, Walsh C. Lessons from natural molecules. Nature 2004; 432: $829-37$

3 Koehn FE, Carter GT. The evolving role of natural products in drug discovery. Nat Rev Drug Discov 2005; 4: 206-20

4 GreefJ van der, McBurney RN. Rescuing drug discovery: in vivo systems pathology and systems pharmacology. Nat Rev Drug Discov 2005; 4 : $961-7$

5 Zon LI, Peterson RT. In vivo drug discovery in the zebrafish. Nat Rev Drug Discov 2005; 4: 35-44

6 Streisinger G, Walker C, Dower N, Knauber D, Singer F. Production of clones of homozygous diploid zebra fish (Brachydanio rerio). Nature $1981 ; 291: 293-6$

7 Haffter P, Granato M, Brand M, Mullins MC, Hammerschmidt M, Kane $D A$ et al. The identification of genes with unique and essential functions in the development of the zebrafish, Danio rerio. Development 1996; $123: 1-36$

8 Driever W, Solnica-Krezel L, Schier AF, Neuhauss SC, Malicki J, Stemple $D L$ et al. A genetic screen for mutations affecting embryogenesis in zebrafish. Development 1996; 123: 37 - 46

9 Amsterdam A, Nissen RM, Sun Z, Swindell EC, Farrington S, Hopkins N. Identification of 315 genes essential for early zebrafish development. Proc Natl Acad Sci USA 2004; 101: $12792-7$
10 Piotrowski T, Schilling TF, Brand M, Jiang YJ, Heisenberg CP, Beuchle D et al. Jaw and branchial arch mutants in zebrafish II: anterior arches and cartilage differentiation. Development 1996; 123: 45- 56

11 Weinstein BM, Schier AF, Abdelilah S, Malicki J, Solnica-Krezel L, Stemple DL et al. Hematopoietic mutations in the zebrafish. Development 1996; 123: $303-9$

12 Stainier DY, Fouquet B, Chen JN, Warren KS, Weinstein BM, Meiler SE et al. Mutations affecting the formation and function of the cardiovascular system in the zebrafish embryo. Development 1996; 123: 285-92

13 Farber SA, Pack M, Ho SY, Johnson ID, Wagner DS, Dosch R et al. Genetic analysis of digestive physiology using fluorescent phospholipid reporters. Science 2001; 292: $1385-8$

14 Jin SW, Herzog W, Santoro MM, Mitchell TS, Frantsve J, Jungblut B et al. A transgene-assisted genetic screen identifies essential regulators of vascular development in vertebrate embryos. Dev Biol 2007; 307: $29-42$

15 Baraban SC, Dinday MT, Castro PA, Chege S, Guyenet S, Taylor MR. A large-scale mutagenesis screen to identify seizure-resistant zebrafish. Epilepsia 2007; 48: 1151 - 7

16 Summerton J, Weller D. Morpholino antisense oligomers: design, preparation, and properties. Antisense Nucleic Acid Drug Dev 1997; 7 : $187-95$

17 Nasevicius A, Ekker SC. Effective targeted gene 'knockdown' in zebrafish. Nat Genet 2000; 26: 216-20

18 Heasman J. Morpholino oligos: making sense of antisense? Dev Biol 2002; 243: 209-14

19 Doitsidou M, Reichman-Fried M, Stebler J, Köprunner M, Dörries J, Meyer $D$ et al. Guidance of primordial germ cell migration by the chemokine SDF-1. Cell 2002; 111: $647-59$

20 Pickart MA, Klee EW, Nielsen AL, Sivasubbu S, Mendenhall EM, Bill BR et al. Genome-wide reverse genetics framework to identify novel functions of the vertebrate secretome. PLoS ONE 2006; 1: e104

21 Esguerra CV, Nelles L, Vermeire L, Ibrahimi A, Crawford AD, Derua R et al. Ttrap is an essential modulator of Smad3-dependent Nodal signaling during zebrafish gastrulation and left-right axis determination. Development 2007; 134: 4381 - 93

22 Shestopalov IA, Sinha S, Chen JK. Light-controlled gene silencing in zebrafish embryos. Nat Chem Biol 2007; 3: 650-1

23 Dodd A, Chambers SP, Love DR. Short interfering RNA-mediated gene targeting in the zebrafish. FEBS Lett 2004; 561: 89-93

24 Summerton JE. Morpholino, siRNA, and S-DNA compared: impact of structure and mechanism of action on off-target effects and sequence specificity. Curr Top Med Chem 2007; 7: 651 -60

25 Wang N, Sun YH, Liu J, Wu G, Su JG, Wang YP et al. Knockdown of gfp and no tail expression in zebrafish embryo by in vivo-transcribed short hairpin RNA with T7 plasmid system. J Biomed Sci 2007; 14: $767-76$

26 Amsterdam A, Becker TS. Transgenes as screening tools to probe and manipulate the zebrafish genome. Dev Dyn 2005; 234: 255-68

27 Beis D, Stainier DY. In vivo cell biology: following the zebrafish trend. Trends Cell Biol 2006; 16: 105-12

28 Lawson ND, Weinstein BM. In vivo imaging of embryonic vascular development using transgenic zebrafish. Dev Biol 2002; 248: $307-18$

29 Tran TC, Sneed B, Haider J, Blavo D, White A, Aiyejorun T et al. Automated, quantitative screening assay for antiangiogenic compounds using transgenic zebrafish. Cancer Res 2007; 67: 11386-92

30 Pisharath H, Rhee JM, Swanson MA, Leach SD, Parsons MJ. Targeted ablation of beta cells in the embryonic zebrafish pancreas using $E$. coli nitroreductase. Mech Dev 2007; 124: 218 - 29

31 Esengil H, Chang V, Mich JK, Chen JK. Small-molecule regulation of zebrafish gene expression. Nat Chem Biol 2007; 3: 154-5

32 Chang YT. Small-molecule switch for zebrafish gene expression. Nat Chem Biol 2007; 3: 135-6

33 Jones RW, Huffman MN. Fish embryos as bio-assay material in testing chemicals for effects on cell division and differentiation. Trans Am Microsc Soc 1957; 76: 177-83

34 Abedi ZH, McKinley WP. Bioassay of captan by zebrafish larvae. Nature 1967; 216: $1321-2$

35 Alestrom P, Holter JL, Nourizadeh-Lillabadi R. Zebrafish in functional genomics and aquatic biomedicine. Trends Biotechnol 2006; 24: 15 21

36 Jones RW, Stout MG, Reich H, Huffman MN. Cytotoxic activities of certain flavonoids against zebra-fish embryos. Cancer Chemother Rep 1964; 34: $19-20$ 
37 Thomas RJ. The toxicologic and teratologic effects of delta-9-tetrahydrocannabinol in the zebrafish embryo. Toxicol Appl Pharmacol 1975; 32 : $184-90$

38 Chang BE, Liao MH, Kuo MY, Chen CH. Developmental toxicity of arecoline, the major alkaloid in betel nuts, in zebrafish embryos. Birth Defects Res A: Clin Mol Teratol 2004; 70: 28 - 36

39 Gertsch J, Niomawe, Gertsch-Roost K, Sticher O. Phyllanthus piscatorum: ethnopharmacological studies on a women's medicinal plant of the Yanomami Amerindians. J Ethnopharmacol 2004; 91: 181 - 8

40 Gertsch J, Tobler RT, Brun R, Sticher O, Heilmann J. Antifungal, antiprotozoal, cytotoxic and piscicidal properties of justicidin B and a new arylnaphthalide lignan from Phyllanthus piscatorum. Planta Med 2003; 69: 420 - 4

41 Peterson RT, Link BA, Dowling JE, Schreiber SL. Small molecule developmental screens reveal the logic and timing of vertebrate development. Proc Natl Acad Sci USA 2000; 97: 12965 -9

42 Spring DR, Krishnan S, Blackwell HE, Schreiber SL. Diversity-oriented synthesis of biaryl-containing medium rings using a one bead/one stock solution platform. J Am Chem Soc 2002; 124: 1354-63

43 MacRae CA, Peterson RT. Zebrafish-based small molecule discovery. Chem Biol 2003; 10: 901 - 8

44 Peterson RT, Shaw SY, Peterson TA, Milan DJ, Zhong TP, Schreiber SL et al. Chemical suppression of a genetic mutation in a zebrafish model of aortic coarctation. Nat Biotech 2004; $22: 595$ - 9

45 Jung DW, Williams D, Khersonsky SM, Kang TW, Heidary N, Chang YT et al. Identification of the F1F0 mitochondrial ATPase as a target for modulating skin pigmentation by screening a tagged triazine library in zebrafish. Mol Biosyst 2005; 1: $85-92$

46 Yang CT, Johnson SL. Small molecule-induced ablation and subsequent regeneration of larval zebrafish melanocytes. Development 2006; 133: $3563-73$

47 Choi TY, Kim JH, Ko DH, Kim CH, Hwang JS, Ahn S et al. Zebrafish as a new model for phenotype-based screening of melanogenic regulatory compounds. Pigment Cell Res 2007; 20: $120-7$

48 Murphey RD, Stern HM, Straub CT, Zon LI. A chemical genetic screen for cell cycle inhibitors in zebrafish embryos. Chem Biol Drug Des 2006; 68: $13-9$

49 Burns CG, Milan DJ, Grande EJ, Rottbauer W, MacRae CA, Fishman MC. High-throughput assay for small molecules that modulate zebrafish embryonic heart rate. Nat Chem Biol 2005; 1: 63-4

50 Mathew LK, Sengupta S, Kawakami A, Andreasen EA, Lohr CV, Loynes CA et al. Unraveling tissue regeneration pathways using chemical genetics. J Biol Chem 2007; 282: 35202 - 10

51 Shafizadeh E, Peterson RT, Lin S. Induction of reversible hemolytic anemia in living zebrafish using a novel small molecule. Comp Biochem Physiol C: Toxicol Pharmacol 2004; 138: 245 -9

52 Lally BE, Geiger GA, Kridel S, Arcury-Quandt AE, Robbins ME, Kock ND et al. Identification and biological evaluation of a novel and potent small molecule radiation sensitizer via an unbiased screen of a chemical library. Cancer Res 2007; 67: 8791 -9

53 Berger J, Currie P. The role of zebrafish in chemical genetics. Curr Med Chem 2007; 14: 2413-20

54 Lam HW, Lin HC, Lao SC, Gao JL, Hong SJ, Leong CWY et al. The angiogenic effects of Angelica sinensis extract on HUVEC in vitro and zebrafish in vivo. J Cell Biochem 2008; 103: 195 - 211

55 He MF, But PPH, Shaw PC, Jiang RW, Xu HX. Anti-angiogenic agents from Tripterygium wilfordii American Society of Pharmacognosy 47th Annual Meeting; Arlington, Virginia: 2006

56 Maule J, Richardson J, Clements C, Harvey A, Patton E. A pilot screen for natural inhibitors of cancer-relevant signaling pathways 5th European Zebrafish Genetics and Development Meeting; Amsterdam: 2007

57 Incardona JP, Gaffield W, Kapur RP, Roelink $H$. The teratogenic Veratrum alkaloid cyclopamine inhibits sonic hedgehog signal transduction. Development 1998; 125: 3553-62

58 D'Amour KA, Bang AG, Eliazer S, Kelly OG, Aqulnick AD, Smart NG et al. Production of pancreatic hormone-expressing endocrine cells from human embryonic stem cells. Nat Biotechnol 2006; 24: 1392 - 401

59 Lauth $M$, Toftgard $R$. The Hedgehog pathway as a drug target in cancer therapy. Curr Opin Invest Drugs 2007; 8: 457-61

60 Lipinski RJ, Dengler E, Kiehn M, Peterson RE, Bushman W. Identification and characterization of several dietary alkaloids as weak inhibitors of Hedgehog signaling. Toxicol Sci 2007; 100: 456-63

61 Crawford AD, Breyne A, Oosterlynk J, Maes J, Dewaele M, Ruzzene M et al. Natural product discovery via chemical genetics in zebrafish 5 th
International Congress and Annual Meeting of the Society for Medicinal Plant Research; Graz: 2007

62 Fong TA, Shawver LK, Sun L, Tang C, App H, Powell TJ et al. SU5416 is a potent and selective inhibitor of the vascular endothelial growth factor receptor (Flk-1/KDR) that inhibits tyrosine kinase catalysis, tumor vascularization, and growth of multiple tumor types. Cancer Res 1999; 59: 99 - 106

63 Yim H, Lee $\mathrm{YH}$, Lee $\mathrm{CH}$, Lee SK. Emodin, an anthraquinone derivative isolated from the rhizomes of Rheum palmatum, selectively inhibits the activity of casein kinase II as a competitive inhibitor. Planta Med 1999; 65: 9-13

64 Wang XH, Wu SY, Zhen YS. Inhibitory effects of emodin on angiogenesis. Yao Xue Xue Bao (Acta Pharm Sin) 2004; 39: 254 - 8

65 Ljubimov AV, Caballero S, Aoki AM, Pinna LA, Grant MB, Castellon R. Involvement of protein kinase CK2 in angiogenesis and retinal neovascularization. Invest Ophthalmol Visc Sci 2004; 45: 4583 - 91

66 Luesch H, Yoshida WY, Moore RE, Paul VJ, Corbett TH. Total structure determination of apratoxin $A$, a potent novel cytotoxin from the marine cyanobacterium Lyngbya majuscula. J Am Chem Soc 2001; 123: $5418-23$

67 Luesch H, Chanda SK, Raya RM, DeJesus PD, Orth AP, Walker JR et al. A functional genomics approach to the mode of action of apratoxin A. Nat Chem Biol 2006; 2: 158 - 67

68 McCowen MC, Callender ME, Lawlis JF Jr. Fumagillin (H-3), a new antibiotic with amebicidal properties. Science 1951; 113: 202 - 3

69 Ingber D, Fujita T, Kishimoto S, Sudo K, Kanamaru T, Brem H et al. Synthetic analogues of fumagillin that inhibit angiogenesis and suppress tumour growth. Nature 1990; 348: $555-7$

70 Satchi-Fainaro R, Puder M, Davies JW, Tran HT, Sampson DA, Greene AK et al. Targeting angiogenesis with a conjugate of HPMA copolymer and TNP-470. Nat Med 2004; 10: $255-61$

71 Sin N, Meng L, Wang MQ Wen JJ, Bornmann WG, Crews CM. The antiangiogenic agent fumagillin covalently binds and inhibits the methionine aminopeptidase, MetAP-2. Proc Natl Acad Sci USA 1997; 94 $6099-7103$

72 Zhang Y, Yeh JR, Mara A, Ju R, Hines JF, Cirone P et al. A chemical and genetic approach to the mode of action of fumagillin. Chem Biol 2006; 13: $1001-9$

73 Peterson RT. A noncanonical path to mechanism of action. Chem Biol 2006; 13: 924-6

74 Braida D, Limonta V, Pegorini S, Zani A, Guerini-Rocco C, Gori E et al. Hallucinatory and rewarding effect of salvinorin A in zebrafish: kappa-opioid and CB1-cannabinoid receptor involvement. Psychopharmacology 2007; 190: $441-8$

75 Ninkovic J, Bally-Cuif L. The zebrafish as a model system for assessing the reinforcing properties of drugs of abuse. Methods 2006; 39: 262 74

76 Yu PB, Hong CC, Sachidanandan C, Babitt JL, Deng DY, Hoyng SA et al. Dorsomorphin inhibits BMP signals required for embryogenesis and iron metabolism. Nat Chem Biol 2008; 4: 33-41

77 Sar AM van der, Appelmelk BJ, Vandenbroucke-Grauls CM, Bitter W. A star with stripes: zebrafish as an infection model. Trends Microbiol 2004; $12: 51-7$

78 Mukhopadhyay A, Peterson RT. Fishing for new antimicrobials. Curr Opin Chem Biol 2006; 10: 327 - 33

79 Pressley ME, Phelan PE 3rd, Witten PE, Mellon MT, Kim CH. Pathogenesis and inflammatory response to Edwardsiella tarda infection in the zebrafish. Dev Comp Immunol 2005; 29: 501 - 13

80 Watzke J, Schirmer K, Scholz S. Bacterial lipopolysaccharides induce genes involved in the innate immune response in embryos of the zebrafish (Danio rerio). Fish Shellfish Immunol 2007; 23: 901 - 5

81 Lieschke GJ, Oates AC, Crowhurst MO, Ward AC, Layton JE. Morphologic and functional characterization of granulocytes and macrophages in embryonic and adult zebrafish. Blood 2001; 98: 3087-96

82 Renshaw SA, Loynes CA, Trushell DM, Elworthy S, Ingham PW, Whyte $M K$. A transgenic zebrafish model of neutrophilic inflammation. Blood 2006; 108: 3976-8

83 Mathias JR, Perrin BJ, Liu TX, Kanki J, Look AT, Huttenlocher A. Resolution of inflammation by retrograde chemotaxis of neutrophils in transgenic zebrafish. J Leukoc Biol 2006; 80: 1281 - 8

84 Redd MJ, Kelly G, Dunn G, Way M, Martin P. Imaging macrophage chemotaxis in vivo: studies of microtubule function in zebrafish wound inflammation. Cell Motil Cytoskeleton 2006; 63: 415-22

85 Baraban SC. Emerging epilepsy models: insights from mice, flies, worms and fish. Curr Opin Neurol 2007; 20: 164-8 
86 Baraban SC, Taylor MR, Castro PA, Baier H. Pentylenetetrazole induced changes in zebrafish behavior, neural activity and c-fos expression. Neuroscience 2005; 131: 759-68

87 Berghmans S, Hunt J, Roach A, Goldsmith P. Zebrafish offer the potential for a primary screen to identify a wide variety of potential anticonvulsants. Epilepsy Res 2007; 75: $18-28$

88 Tiedeken JA, Ramsdell JS. Embryonic exposure to domoic acid increases the susceptibility of zebrafish larvae to the chemical convulsant pentylenetetrazole. Environ Health Perspect 2007; 115: 1547-52

89 Milan DJ, Peterson TA, Ruskin JN, Peterson RT, MacRae CA. Drugs that induce repolarization abnormalities cause bradycardia in zebrafish. Circulation 2003; 107: $1355-8$

90 Langheinrich $U$, Vacun G, Wagner T. Zebrafish embryos express an orthologue of HERG and are sensitive toward a range of QT-prolonging drugs inducing severe arrhythmia. Toxicol Appl Pharmacol 2003; 193 : $370-82$

91 Heideman W, Antkiewicz DS, Carney SA, Peterson RE. Zebrafish and cardiac toxicology. Cardiovasc Toxicol 2005; 5: 203-14

92 Arnaout R, Ferrer T, Huisken J, Spitzer K, Stainier DY, Tristani-Firouzi M et al. Zebrafish model for human long QT syndrome. Proc Natl Acad Sci USA 2007; 104: 11316-21

93 Le X, Langenau DM, Keefe MD, KutokJL, Neuberg DS, Zon LI. Heat shockinducible Cre/Lox approaches to induce diverse types of tumors and hyperplasia in transgenic zebrafish. Proc Natl Acad Sci USA 2007; 104: $9410-5$

94 Feng H, Langenau DM, Madge JA, Quinkertz A, Gutierrez A, Neuberg DS et al. Heat-shock induction of T-cell lymphoma/leukaemia in conditional Cre/lox-regulated transgenic zebrafish. Br J Haematol 2007; 138: $169-75$

95 Langenau DM, Feng H, Berghmans S, Kanki JP, Kutok JL, Look AT. Cre/ lox-regulated transgenic zebrafish model with conditional myc-induced T cell acute lymphoblastic leukemia. Proc Natl Acad Sci USA 2005; 102: $6068-73$

96 Berghmans S, Murphey RD, Wienholds E, Neuberg D, Kutok JL, Fletcher $C D$ et al. tp53 mutant zebrafish develop malignant peripheral nerve sheath tumors. Proc Natl Acad Sci USA 2005; 102: 407-12

97 Mizgireuv IV, Revskoy SY. Transplantable tumor lines generated in clonal zebrafish. Cancer Res 2006; 66: 3120-5

98 Goessling W, North TE, Zon LI. Ultrasound biomicroscopy permits in vivo characterization of zebrafish liver tumors. Nat Methods 2007; 4: $551-3$

99 Topczewska JM, Postovit LM, Margaryan NV, Sam A, Hess AR, Wheaton $W W$ et al. Embryonic and tumorigenic pathways converge via Nodal signaling: role in melanoma aggressiveness. Nat Med 2006; 12: $925-32$

100 Haldi M, Ton C, Seng WL, McGrath P. Human melanoma cells transplanted into zebrafish proliferate, migrate, produce melanin, form masses and stimulate angiogenesis in zebrafish. Angiogenesis 2006; 9: $139-51$

101 Nicoli S, Ribatti D, Cotelli F, Presta M. Mammalian tumor xenografts induce neovascularization in zebrafish embryos. Cancer Res 2007; 67: $2927-31$

102 Hendrix MJ, Seftor EA, Seftor RE, Kasemeier-Kulesa J, Kulesa PM, Postovit LM. Reprogramming metastatic tumour cells with embryonic microenvironments. Nat Rev Cancer 2007; 7: 246-55

103 Geiger GA, Parker SE, Beothy AP, Tucker JA, Mullins MC, Kao GD. Zebrafish as a "biosensor"? Effects of ionizing radiation and amifostine on embryonic viability and development. Cancer Res 2006; 66: 817281

104 Moore JL, Rush LM, Breneman C, Mohideen MA, Cheng KC. Zebrafish genomic instability mutants and cancer susceptibility. Genetics 2006; 174: $585-600$

105 Shepard JL, Amatruda JF, Stern HM, Subramanian A, Finkelstein D, Ziai J et al. A zebrafish bmyb mutation causes genome instability and increased cancer susceptibility. Proc Natl Acad Sci USA 2005; 102: 13194-9

106 Stern HM, Murphey RD, Shepard JL, Amatruda JF, Straub CT, Pfaff KL et al. Small molecules that delay $\mathrm{S}$ phase suppress a zebrafish bmyb mutant. Nat Chem Biol 2005; 1: 366 - 70
107 Arbiser JL, Kau T, Konar M, Narra K, Ramchandran R, Summers SA et al. Solenopsin, the alkaloidal component of the fire ant (Solenopsis invicta), is a naturally occurring inhibitor of phosphatidylinositol-3kinase signaling and angiogenesis. Blood 2007; 109: 60-5

108 Langenau DM, Traver D, Ferrando AA, Kutok JL, Aster JC, Kanki JP et al. Myc-induced T cell leukemia in transgenic zebrafish. Science 2003; 299: $887-90$

109 McAleer MF, Davidson C, Davidson WR, Yentzer B, Farber SA, Rodeck U et al. Novel use of zebrafish as a vertebrate model to screen radiation protectors and sensitizers. Int J Radiat Oncol Biol Phys 2005; 61 : 10 3

110 Fleming A, Sato M, Goldsmith P. High-throughput in vivo screening for bone anabolic compounds with zebrafish. J Biomol Screen 2005; 10: $823-31$

111 Barrett R, Chappell C, Quick M, Fleming A. A rapid, high content, in vivo model of glucocorticoid-induced osteoporosis. Biotechnol J 2006; 1 : $651-5$

112 Jagadeeswaran P, Paris $R$, Rao P. Laser-induced thrombosis in zebrafish larvae: a novel genetic screening method for thrombosis. Methods Mol Med 2006; 129: 187-95

113 Lockwood B, Bjerke S, Kobayashi K, Guo S. Acute effects of alcohol on larval zebrafish: a genetic system for large-scale screening. Pharmacol Biochem Behav 2004; 77: 647 - 54

114 Darland T, Dowling JE. Behavioral screening for cocaine sensitivity in mutagenized zebrafish. Proc Natl Acad Sci USA 2001; 98: 11691-6

115 Saint-Amant L, Sprague SM, Hirata H, Li Q Cui WW, Zhou W et al. The zebrafish ennui behavioral mutation disrupts acetylcholine receptor localization and motor axon stability. Dev Neurobiol 2007; 68: $45-$ 61

116 Best JD, Berghmans S, Hunt JJ, Clarke SC, Fleming A, Goldsmith P et al. Non-associative learning in larval zebrafish Neuropsychopharmacology; June 20 2007, DOI: 10.1038/sj.npp.1301489

117 Hicks C, Sorocco D, Levin M. Automated analysis of behavior: a computer-controlled system for drug screening and the investigation of learning. J Neurobiol 2006; 66: 977-90

118 Kuhlman J, Eisen JS. Genetic screen for mutations affecting development and function of the enteric nervous system. Dev Dyn 2007; 236: $118-27$

119 Pogoda HM, Sternheim N, Lyons DA, Diamond B, Hawkins TA, Woods IG et al. A genetic screen identifies genes essential for development of myelinated axons in zebrafish. Dev Biol 2006; 298: 118- 31

120 Kazakova N, Li H, Mora A, Jessen KR, Mirsky R, Richardson WD et al. A screen for mutations in zebrafish that affect myelin gene expression in Schwann cells and oligodendrocytes. Dev Biol 2006; 297: 1-13

121 Tomasiewicz HG, Flaherty DB, Soria JP, Wood JG. Transgenic zebrafish model of neurodegeneration. J Neurosci Res 2002; 70: 734-45

122 Lemmens R, Van Hoecke A, Hersmus N, Geelen V, D'Hollander I, Thijs V et al. Overexpression of mutant superoxide dismutase 1 causes a motor axonopathy in the zebrafish. Hum Mol Genet 2007; 16: 2359-65

123 Kim HJ, Sumanas S, Palencia-Desai S, Dong Y, Chen JN, Lin S. Genetic analysis of early endocrine pancreas formation in zebrafish. Mol Endocrinol 2006; 20: $194-203$

124 Ober EA, Verkade H, Field HA, Stainier DY. Mesodermal Wnt2b signalling positively regulates liver specification. Nature 2006; 442: 688 91

125 Sadler KC, Amsterdam A, Soroka C, Boyer J, Hopkins N. A genetic screen in zebrafish identifies the mutants vps $18, n f 2$ and foie gras as models of liver disease. Development 2005; 132: 3561 - 72

126 Ton C, Parng $C$. The use of zebrafish for assessing ototoxic and otoprotective agents. Hear Res 2005; 208: 79-88

127 Ou HC, Raible DW, Rubel EW. Cisplatin-induced hair cell loss in zebrafish (Danio rerio) lateral line. Hear Res 2007; 233: 46 - 53

128 DeBruyne J, Hurd MW, Gutiérrez L, Kaneko M, Tan Y, Wells DE et al. Isolation and phenogenetics of a novel circadian rhythm mutant in zebrafish. J Neurogenet 2004; 18: 403-28

$129 \mathrm{Kim}$ JH, Baek SH, Kim DH, Choi TY, Yoon TY, Hwang JS et al. Downregulation of melanin synthesis by haginin $A$ and its application to in vivo lightening model. J Invest Dermatol 2007; DOI: 10.1038/sj.jid. 5701177 